\title{
VALIDAÇÃO DE INSTRUMENTOS PARA DOCUMENTAÇÃO DO PROCESSO DE ENFERMAGEM EM UNIDADE DE TERAPIA INTENSIVA
}

\author{
Roberta Nazario Aoki ${ }^{1}$ \\ Margareta Maria Wolpereis Groot ${ }^{2}$ \\ Marcos Aurélio Boes ${ }^{3}$ \\ Danilo Donizetti Trevisan ${ }^{4}$ \\ Ana Railka de Oliveira ${ }^{5}$ \\ ${ }^{1,3}$ Supervisores de Enfermagem da Unidade de Terapia Intensiva do \\ Hospital das Clínicas da Unicamp \\ ${ }^{2}$ Diretora de Enfermagem da Unidade de Terapia Intensiva do \\ Hospital das Clínicas da Unicamp \\ ${ }^{4}$ Professor Doutor da Universidade Federal de São João del Rei - UFSJ \\ ${ }^{5}$ Professora Doutora da Faculdade de Enfermagem da Unicamp
}

INTRODUÇÃO: O Processo de Enfermagem (PE) é recurso metodológico para o planejamento e registro das ações práticas dos enfermeiros. Em terapia intensiva, a identificação das condições apresentadas pelos pacientes, bem como as intervenções de enfermagem pautadas em resultados esperados para cada perfil, têm contribuído para a práticas seguras e conferido maior visibilidade aos cuidados de enfermagem. Apesar da reconhecida importância, muitas instituições enfrentam dificuldades na implantação do PE, algumas relativas ao processo de trabalho, aos escassos recursos humanos e recursos tecnológicos. Diante disso, a padronização de linguagens especiais de enfermagem foi desenvolvida para auxiliar e qualificar a prestação dos cuidados, sendo os sistemas NANDA-I, NOC e NIC (NNN) utilizados mundialmente em instrumentos de sistematização dos cuidados em Enfermagem. OBJETIVO: Validar o conteúdo de um instrumento para o Processo de Enfermagem utilizando os sistemas de linguagem da NANDA-I, NOC e NIC (NNN) em uma Unidade de Terapia Intensiva. MÉTODO: Estudo metodológico desenvolvido no período de junho a setembro de 2015 em uma Unidade de Terapia Intensiva de um hospital universitário do interior de São Paulo e conduzido em três etapas: (1) construção dos instrumentos para o PE utilizando os sistemas de linguagem NANDA-I, NOC e NIC; (2) submissão à apreciação de 13 juízes especialistas em ensino e Terapia Intensiva, (3) verificação da aplicabilidade e julgamento do conteúdo quanto a clareza, facilidade de leitura e apresentação por 40 enfermeiros assistenciais. O estudo foi aprovado pelo Comitê de Ética em Pesquisa, registro CAAE: 64519617.80005404. Utilizou-se o software Statistical 
Analysis System (SAS) versão 9.2 para realização dos cálculos de Índice de Validação de Conteúdo (IVC) e Índice Kappa. RESULTADOS: Os instrumentos foram validados com o IVC e Kappa acima de 0,8 na maioria de todas as variáveis e os enfermeiros participantes do estudo consideraram que o conteúdo dos impressos apresentava-se de forma clara, de fácil leitura e aplicação. CONCLUSÃO: O instrumento pode ser considerado válido em seu conteúdo e de fácil implementação do Processo de Enfermagem de na prática assistencial.

Palavras-chave: Processo de enfermagem. Validação. Cuidados críticos. 